Article

\title{
Networked or Un-Networked? A Preliminary Study on KIBS-Based Sustainable Urban Development: The Case of China
}

\author{
Kunhui Ye ${ }^{1}$, Guo Liu ${ }^{2, *}$ and Yongwei Shan ${ }^{3}$ \\ 1 Research Center for Construction Economics and Management, School of Construction Management and \\ Real Estate, Chongqing University, Chongqing 400045, China; Kunhui.Ye@Gmail.com \\ 2 International Research Center for Sustainable Built Environment, School of Construction Management and \\ Real Estate, Chongqing University, Chongqing 400045, China \\ 3 School of Civil and Environmental Engineering, Oklahoma State University, Stillwater 74078, USA; \\ yongwei.shan@okstate.edu \\ * Correspondence: lgjycqu@163.com; Tel.: +86-159-2261-3085
}

Academic Editor: Tan Yigitcanlar

Received: 27 March 2016; Accepted: 24 May 2016; Published: 27 May 2016

\begin{abstract}
Increasingly pertinent linkages of cities via knowledge intensive business services (KIBS) in the 21st century have opened a new window for academia to reconsider the approach to achieving urban sustainability. In this study, city network was investigated with an aim of identifying its attributes in the framework of sustainable urban development. Data about China's KIBS, which are compiled in an inter-regional input-output table, were calculated following the procedure of social network analysis. It was found that: (1) the degree of nodes (i.e., out-degree, in-degree and betweenness) in China varies distinctively from city to city; (2) the hierarchy of the city network is very tiny; and (3) that the network structure is subject to both "a small world" and core-periphery effects. Furthermore, city nodes in China fall into four categories, namely high centrality and power, high centrality and low power, low centrality and high power, and low centrality and power. The implication is that governmental efforts should be made to secure a reasonable decentralization of key city nodes to ensure that urban sustainability is built on a city-to-city basis.
\end{abstract}

Keywords: urban sustainability; city network; knowledge intensive business services; social network analysis

\section{Introduction}

A city functions as a pool in accumulating social capitals to accommodate human activities. However, recent years have witnessed a larger magnitude of cities that are faced with a crossroad in the way towards social, economic, and environmental sustainability. Problems including poverty, unbalanced urban configuration, and greenhouse gas continue arising and they have aggregated the difficulty in actualizing the target of sustainability as a consequence [1]. In developing countries, urban sustainability is still heavily reliant on the growth of economy. Whilst the efficiency and effectiveness of scarce resources utilization are unavoidably prioritized, great efforts are advocated to minimize negative impacts on the environment at the same time [2]. In this connection, researchers have stressed the importance of pursuing knowledge-based urban development (KBUD) [3,4]. One of the primary reasons is that knowledge services constitute a primary sector of economy that yields considerable employment opportunities. Furthermore, social and environmental sustainability will be weakened in the long run if this sector is subject to a shrinking situation [5]. Promoting sustainability through the creation and exchange of knowledge services in an environmentally conserved, economically secure, socially just and well governed human setting is thus meaningful to urban development [6]. 
With the advent of economic integration and globalization in the current century, cities are linked to each other in a more frequent, diversified and tighter fashion than before. In effect, cities' linkages spread broadly over territories and numerous borderless urban regions appear, leading to the emergence of city networks in various sizes [7]. The occurrence of a city network suggests that urban sustainability has to interpret those inherent contact, exchange and communication between cities [8-10]. Whilst the subject of city network is a heated issue in the field of urban studies [7-9,11], previous studies are often criticized for the shortage of valid data as well as the lack of theoretical foundation, construct and implications in developing countries [12-15]. First, given the growing multidimensional connectivity of industrial sectors (e.g., advanced producer services), what kind of city network really matters to urban development has not been explored in a clear and lucid style [15-17]. Second, most of city networks are covert $[12,18]$, and how to uncover them properly remains unknown; Third, in comparison to those major cities such as New York, London and Tokyo in the world, city networks at a national level have not yet received much consideration in academia [13]. As a result, the extent to which a city network favors the achievement of urban sustainability is inexplicit.

Identifying the attributes of a city network is a basic step of addressing the role that the network plays in the domain of urban sustainability. Two elements, namely degree of network node and network structure, can be used [18]. A world city owns a prominent position in a multilayered city network, and it exerts much influence over other cities [12,19]. Such influence is called degree, a term that was proposed to describe a city's power and centrality in the network [20]. In appreciated a couple of factors including location, culture, economy and historical backgrounds, previous studies have pinpointed that not all cities have identical degrees even though they share a common network [21]. Hence, a city's degree must be detected first to underscore the formulation of urban development initiatives, which in turn advances the structure of the city network to match the tenets of urban sustainability [22].

The economic composition of cities around the globe has gradually shifted to be service-dominated since the beginning of this century [23]. Knowledge intensive business services (KIBS) is an industrial sector composed of architecture, engineering, accounting, auditing, feasibility study, strategy management, and other consulting activities that are in essence knowledge-intensive [24]. KIBS is produced, purchased and consumed mainly in cities, and it is characterized by frequent geographical interaction, openness, and dynamics [25,26]. These characteristics manifest that KIBS can be a useful perspective for researchers to examine city networks, either outwards (sending to or influencing) or inwards (received from or being influenced) [26]. By means of knowledge platform, for instance, Malaysia has sustained a high level of sustainable economic and socio-spatial growth, and eventually erected global competitiveness [27]. Furthermore, evidences from developed countries have outlines the positive effects of KIBS on sustainable development [28]. In view of research gaps as presented above, the aim of this study is thus to identify the attributes of city network with to the degree of city nodes and the structure of KIBS-based city network. By doing so, a city network can be utilized in due ways to satisfy the triple bottom lines of urban sustainability.

\section{Literature Review}

\subsection{City Network}

A city is situated more or less in an extended network of urban activities [29]. There are two types of intercity linkages-vertical and horizontal. The former presents the connectivity between hierarchically ordered cities at various levels, while the latter refers to the connectivity between cities at the same level $[7,11,30]$. According to the central place theory, an urban spatial structure is solely representative of vertical linkages [11]. Nonetheless, this point of view was challenged by researchers who hinted at a new urban spatial configuration to explain urban orders $[7,11,30]$. A new camp of thoughts assumes that vertical intercity linkages should not be overemphasized, instead they are blending with horizontal ones; and intercity linkages are interdependent $[7,30]$. This so-called new 
urban order employs a practical perception of intercity relationships, or "city network", to map out city linkages both vertically and horizontally. Furthermore, a city network has spatial linkages (or, space of flows) such as flows, exchanges, nodes, and edges [19].

A city network has in nature multi-dimensional attributes. A typical approach to image a city network is through Taylor's interlocking world city network model (IWCNM) that is built on four intercity relational matrices-elemental, proportional, distance, and asymmetric [31]. IWCNM offers a starting point for quantitative examination of city networks [11]. However, some facets such as the degree of city nodes and the structure of city network are still not interpretable [16,32]. A city network is an application of generic network, in which cities are the nodes, while the flow and exchange of information, commodities, service, and population form the edges [33]. In view of this, researchers have claimed to improve the efficiency of the IWCNM approach by adhering to the principles of networking particularly when relational data are available [19]. Using relational data models [20], for instance, the measurement of betweenness could reflect the degree of a node in a network; the core-periphery measurement quantifies a network's structure by classifying all the relevant nodes into several groups as inherent ties.

\subsection{Inter-Regional Input-Output Table}

A city network is composed of diverse linkages that elaborate human mobility, capital contact, and commodities flow. Mapping out all kinds of city linkages within a magnitude of cities appears to be a daunting task. However, as demonstrated by Friedmann and Wolff [21], the linkages of city networks at a global scale are embedded in production chains or market relationships between major cities. Sassen (1991) employed the linkages of service and financial industries to elaborate the concept of global city network. Furthermore, there are some other intercity linkages such as aviation network, Internet network, and advanced producers network that aim for city networks [8,32]. These studies added fertile to a perception of city network in terms of complexity and variability, and the implication is that the attributes of a city network should embody the connection of one or more economic sectors between cities.

Input-output (I/O) analysis is a scientific approach to examining any relationships that different sectors are engaged in an economic entity [34]. This approach delineates how one industry affects another in a nation or region, and deems the effects as spatial connection and interplays between regions [28,35-37]. In the field of economic geography, the application of I/O analysis requires data about investment and other economic activities [37,38], which are usually tabulated in an inter-regional I/O table, a matrix that utilizes relational data to describe element flow (e.g., consumption and demand) from one region to another [39]. The inter-regional I/O table is a basic matrix that could be further calculated for other potential applications [40]. Direct consumption coefficient table is one of the I/O tables illustrating technical and economic linkages between regions [40,41]. The greater the coefficient, the closer the inter-regional linkages, suggesting that this coefficient table exhibits inter-regional relationships in a network [42]. The inter-regional I/O table is compiled through a large-scale investigation and robust calculation, and it has the advantage of relaying comprehensive and useful information for use $[43,44]$.

KIBS offers problem-oriented tailored services to clients by inputs of human capital and specialist knowledge, characterized by knowledge demand-driven [45], dynamic flow [46], and collaborative interaction [47]. Based on these features, the location of KIBS is arguably determined by geographical proximity to customers, linkage with clients, accessibility of good information, and availability of skilled staff and technological capital [48]. In effect, coupled with better economic competitiveness, abundance in services, and attractiveness for large firms, KIBS firms prefer locating themselves in those urban areas, particularly in large and capital cities $[49,50]$. Indifferent preference on the options of location enables KIBS to connect each other easily at an international, national or provincial level [46,51]. The connection of KIBS underpins the dynamic flows of intellect and knowledge capital between regions, leading to collective development of this sector in a country. In this sense, previous studies 
have stated that the inter-regional I/O table has the potential of seizing the flows between different regions [34].

\subsection{Social Network Analysis}

Social network analysis treats social relations and social structure as a network with two fundamentals [20]: (1) nodes that are in reality supposed to be individuals, companies, counties, cities or countries; and (2) links describing relationships or flows between nodes. Initially, however, the SNA approach was developed to detect individuals' relationships in light of the graph theory and mathematical methods [52,53]. Later on, SNA was consolidated to account for nodes' linkages $[18,20]$. This approach has won much application in the disciplines of sociology, psychology, economics, and management. With the assistance of SNA, it is thought that the properties of nodes, edges and the whole network can be more detectable [54].

A wealth of generic SNA approaches serve as stepping stones for similar research in the field of urban studies $[12,19,54]$. SNA tends to be advantageous when applying to address urban development issues [12]. Given the availability of data for SNA, the degrees of city nodes (i.e., centrality, power) as well as the structure of city network (i.e., network hierarchy, "a small world" and core-periphery) may be illustrated [18]. There are a variety of SNA approaches (e.g., degree analysis) that can be adopted to measure a node in a city network to indicate its influence and position in the network [12]. Meanwhile, accordingly to Liu [20], "a small world" analysis and core-periphery analysis can be used to examine a network structure with respect to both hierarchy and clique membership of city network [19]. Therefore, it is acceptable to adopt the SNA approach in this study.

\section{Methodology}

\subsection{Variables}

As a specific SNA approach, the whole-network analysis functions well in identifying the attributes of city nodes and network structure by treating each node as an object [20]. The degree of nodes in the city network was assessed using three indicators, namely out-degree, in-degree and betweenness, while network structure was measured using four indicators, namely hierarchy, average distance, compactness and core-periphery. These variables are defined as shown in Table 1.

Table 1. Variables of degree and structure of city network.

\begin{tabular}{|c|c|c|c|c|}
\hline Item & Indicator & Definition & Range & Reference \\
\hline \multirow{3}{*}{$\begin{array}{l}\text { Degree of a city } \\
\text { node }\end{array}$} & Out-degree & $\begin{array}{l}\text { The ability of a city node in sending external ties to } \\
\text { others, indicating the node's outflow effects and } \\
\text { centrality in the network. }\end{array}$ & $\mathrm{n} / \mathrm{a}$ & {$[12,22,44]$} \\
\hline & In-degree & $\begin{array}{l}\text { The ability of a city node in receiving internal ties from } \\
\text { others, indicating the node's inflow effects and } \\
\text { centrality in the network. }\end{array}$ & $\mathrm{n} / \mathrm{a}$ & {$[12,22,44]$} \\
\hline & Betweenness & $\begin{array}{l}\text { The ability of a city node to control elements flow to } \\
\text { other nodes and to be brokers of all exchanges, } \\
\text { indicating a node's power. }\end{array}$ & $\mathrm{n} / \mathrm{a}$ & {$[12,20]$} \\
\hline \multirow{4}{*}{$\begin{array}{l}\text { Structure of city } \\
\text { network }\end{array}$} & Hierarchy & $\begin{array}{l}\text { The extent of asymmetrical reachability, and the } \\
\text { hierarchical structure of city network. }\end{array}$ & {$[0,1]$} & [20] \\
\hline & Average distance & $\begin{array}{l}\text { Average distance of the shortest route between any of } \\
\text { two nodes, indicating "a small world" effect. }\end{array}$ & {$[1,+\infty]$} & [20] \\
\hline & Compactness & $\begin{array}{l}\text { The mean of density coefficient of each node, also } \\
\text { indicating "a small world" effect. }\end{array}$ & {$[0,1]$} & [20] \\
\hline & Core-periphery & $\begin{array}{l}\text { The position of core and periphery, indicating the } \\
\text { relationship between the structures of city network. }\end{array}$ & $\mathrm{n} / \mathrm{a}$ & [20] \\
\hline
\end{tabular}




\subsection{Data}

It is quite hard, if not impossible, to gather relational data for any quantitative study of city network. In China, an inter-regional input-output (I/O) table was released jointly by the National Bureau of Statistics, the National Development and Reform Commission, and Ministry of Finance [43]. The latest inter-regional I/O table was published in 2014. This table views all cities in a province as a whole object, and data from thirty industries such as agriculture, forestry, animal husbandry and fishery industry, construction industry and "other services" for the year of 2010 were combined. In the inter-regional I/O table, a city node is measured using relational data collected from all of the sectors. In considering that over $70 \%$ of the subsectors are concerned with knowledge-based services, the data of "other services" were found appropriate to reflect KIBS.

The inter-regional I/O table in China was compiled by means of the approach of I/O analysis, which has gained extensive applications in advanced economies. The latest inter-regional I/O table is based on a nationwide survey on investment and consumption over years. Over 500 large enterprises from various industries were surveyed and inter-regional input structure and product flows for about 100 enterprise groups were sampled. The table was documented with reference to the consumption coefficients of industries (such as agriculture, industry and energy), which were derived from the 2007 I/O table. In light of the work by Taylor et al. [55] that explored connectivity in China's city network based on 2010 data, the inter-regional I/O table of 2010 is considered to be a useful dataset for this study. In effect, such an I/O analytical approach in China was learned from developed countries (e.g., European community); relational data might not be available in developing countries but the procedure described above can arguably be adopted to produce an inter-regional I/O table for the same purpose.

The direct consumption coefficients of $a_{i j}$ (KIBS) of city nodes for pairs $i$ and $j$ is given below and the coefficients are listed in Table 2.

$$
a_{i j}(\text { KIBS })=\frac{x_{i j}}{x_{i}}
$$

where $x_{i}$ represents the total input of KIBS by city $i$, and $x_{i j}$ is the intermediate demand of KIBS by city node $i$ from city node $j$.

Table 2. The direct consumption coefficients of KIBS.

\begin{tabular}{ccccccc}
\hline City Node & Beijing & Tianjin & Hebei & $\ldots$ & Ningxia & Xinjiang \\
\hline Beijing & 0.115 & 0.002 & 0.002 & $\ldots$ & 0.003 & 0.001 \\
Tianjin & 0.000 & 0.091 & 0.001 & $\ldots$ & 0.001 & 0.000 \\
Hebei & 0.000 & 0.001 & 0.068 & & 0.002 & 0.000 \\
$\ldots$ & $\ldots$ & $\ldots$ & $\ldots$ & $\ldots$ & $\ldots$ & $\ldots$ \\
Ningxia & 0.000 & 0.000 & 0.000 & $\ldots$ & 0.062 & 0.000 \\
Xinjiang & 0.000 & 0.000 & 0.000 & $\ldots$ & 0.000 & 0.055 \\
\hline \multicolumn{7}{c}{ Sources: [56]. }
\end{tabular}

The calculation of the degree of city nodes and structure of city network based on the coefficients in Table 2 contains three steps. First, a topology-based network was employed to illustrate the table visually. In the topology, thirty provinces and cities act as the network nodes for simplicity; the edges of the network refer to the tie strength between city nodes. Second, using the software package Ucinet 6, in-degree and out-degree were computed to identify the directions of a city node. It is noted that the direct consumption coefficients in the KIBS table have the property of $a_{i j} \neq a_{j i}$, implying an asymmetry of two city nodes in supplying services to and in receiving services from each other. This data characteristic indicates a discrepancy of a city node between the external linkages and the internal linkages. The existence of discrepancy suggests that a city node has directions of intercity linkages, which is indicated by the edges with arrows in the topology. Lastly, three SNA approaches, 
namely connectivity analysis, small world analysis, and core-periphery analysis were used to quantify the structure of the whole city network.

\section{Results of Data Analysis}

The topology network shown in Figure 1 is formulated on the basis of Table 2. This topological figure indicates a shape of a laying tree with lush branches. It seems therefore that apart from Neimenggu, a vast majority of city nodes in China have many edges, indicating that the network linkages are compact.

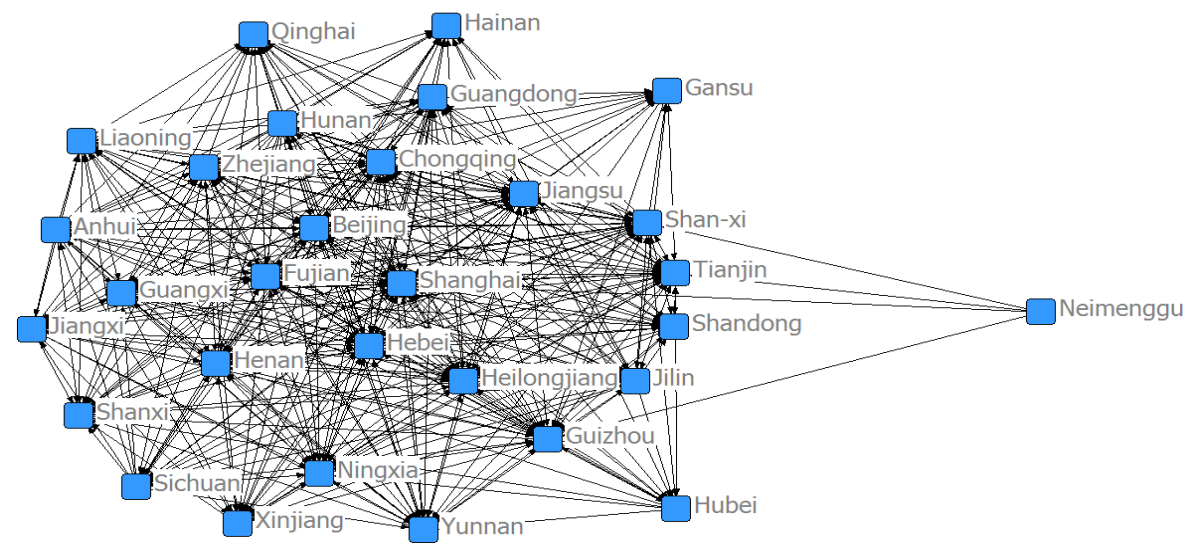

Figure 1. General topology of city network in China.

The resulting coefficients for the degree of city nodes are given in Table 3 . It can be found that all of the out-degrees and the in-degrees are small, ranging from 0.028 to 0.17 ; the overall gap of betweenness is large, varying from 0.000 to 70.250 . Forty-seven percent of city nodes have a greater in-degree than out-degree; $40 \%$ have a larger out-degree; and $27 \%$ of city nodes have a betweenness of 0.000. In addition, both out-degree and in-degree have an equal mean (0.090) and a small standard deviation, being 0.032 and 0.030 , respectively; and the mean of betweenness is 8.467 , with a large standard deviation of 15.303 . These coefficients show that $43 \%, 47 \%$ and $33 \%$ of city nodes have larger out-degree, in-degree and betweenness than the average levels, respectively.

Table 3. Degree coefficients of city nodes in China.

\begin{tabular}{ccccccc}
\hline Rank & City Node & Out-Degree & City Node & In-Degree & City Node & Betweenness \\
\hline 1 & Shanghai & 0.167 & Shanghai & 0.171 & Shanghai & 70.250 \\
2 & Beijing & 0.152 & Guangdong & 0.132 & Tianjin & 43.250 \\
3 & Guangdong & 0.134 & Qinghai & 0.126 & Shan-xi & 25.000 \\
4 & Jilin & 0.124 & Beijing & 0.120 & Hebei & 23.500 \\
5 & Qinghai & 0.122 & Jilin & 0.119 & Guizhou & 16.240 \\
6 & Sichuan & 0.120 & Liaoning & 0.118 & Chongqing & 13.221 \\
7 & Liaoning & 0.118 & Sichuan & 0.118 & Fujian & 10.651 \\
8 & Jiangsu & 0.108 & Jiangsu & 0.107 & Heilongjiang & 10.453 \\
9 & Tianjin & 0.103 & Tianjin & 0.106 & Beijing & 10.354 \\
10 & Hunan & 0.101 & Shanxi & 0.103 & Jiangsu & 9.811 \\
11 & Shanxi & 0.098 & Anhui & 0.097 & Henan & 6.726 \\
12 & Anhui & 0.098 & Fujian & 0.097 & Zhejiang & 5.523 \\
13 & Fujian & 0.097 & Hunan & 0.095 & Jilin & 3.084 \\
14 & Henan & 0.089 & Henan & 0.093 & Guangxi & 2.617 \\
15 & Hubei & 0.089 & Shandong & 0.089 & Guangdong & 0.802 \\
16 & Shandong & 0.088 & Hubei & 0.089 & Anhui & 0.706 \\
17 & Hebei & 0.087 & Yunnan & 0.087 & Yunnan & 0.447 \\
18 & Chongqing & 0.085 & Jiangxi & 0.086 & Liaoning & 0.437 \\
\hline
\end{tabular}


Table 3. Cont.

\begin{tabular}{ccccccc}
\hline Rank & City Node & Out-Degree & City Node & In-Degree & City Node & Betweenness \\
\hline 19 & Zhejiang & 0.084 & Chongqing & 0.084 & Jiangxi & 0.326 \\
20 & Jiangxi & 0.084 & Zhejiang & 0.082 & Ningxia & 0.250 \\
21 & Yunnan & 0.081 & Ningxia & 0.078 & Hunan & 0.225 \\
22 & Hainan & 0.073 & Hebei & 0.076 & Sichuan & 0.125 \\
23 & Shan-xi & 0.068 & Hainan & 0.076 & Shanxi & 0.000 \\
24 & Gansu & 0.068 & Gansu & 0.069 & Neimenggu & 0.000 \\
25 & Ningxia & 0.063 & Heilongjiang & 0.064 & Shandong & 0.000 \\
26 & Heilongjiang & 0.058 & Shan-xi & 0.063 & Hubei & 0.000 \\
27 & Xinjiang & 0.056 & Xinjiang & 0.058 & Hainan & 0.000 \\
28 & Guizhou & 0.037 & Guizhou & 0.045 & Gansu & 0.000 \\
29 & Neimenggu & 0.033 & Neimenggu & 0.033 & Qinghai & 0.000 \\
30 & Guangxi & 0.028 & Guangxi & 0.029 & Xinjiang & 0.000 \\
\cline { 2 - 6 } & Mean & 0.090 & Mean & 0.090 & Mean & 8.467 \\
\hline
\end{tabular}

The derived coefficients of network structure with respect to hierarchy, average distance, compactness and core-periphery are listed in Table 4. As shown in the table, the hierarchy has a smaller value; the average distance symbolizes that the city network takes 1.184 lines on average from one city node to another; and the compactness indicates a close interconnection between nodes, which can echo the compact topology indicated in Figure 1. The core-periphery classifies all city nodes into two types-core and periphery. Based on these clusters, Beijing and Shanghai stay at the core of the city network, and $99.3 \%$ of city nodes are located in the periphery.

Table 4. Results of quantifying the structure of city network in China.

\begin{tabular}{cc}
\hline Indicator & Outputs \\
\hline Hierarchy & 0.131 \\
Average distance & 1.184 \\
Compactness & 0.908 \\
& Core area: Beijing, Shanghai; Periphery area: Tianjin, Hebei, Shanxi, Neimenggu, \\
& Liaoning, Jilin, Heilongjiang, Jiangsu, Zhejiang, Anhui, Fujian, Jiangxi, Shandong, \\
Core-periphery & Henan, Hubei, Hunan, Guangdong, Guangxi, Hainan, Chongqing, Sichuan, \\
& Guizhou, Yunnan, Shan-xi, Gansu, Qinghai, Ningxia, Xinjiang \\
\hline
\end{tabular}

\section{Findings and Discussion}

\subsection{Outflow and Inflow Effect of City Nodes}

As shown in Table 3, not all in-degrees of city nodes in China are equal to out-degrees, signaling that each city might have asymmetric connectivity. The out-degree and in-degree of Shanghai, Beijing and Guangdong can be ranked as the top three, which suggests that they have greater connectivity than other cities. This finding concurs with the study by Taylor et al. [55], which was an effort to rank Chinese cities in the globe. The different effects between outflow and inflow deserve much attention in the formulation of sustainable urban development in the country. According to Taylor [29], a city will find it hard to prosper without connecting to or being connected by other cities especially for the time being. This is the case in China as both in-degrees and out-degrees are detectable. In fact, intercity linkages surface nationwide and urban development exhibits a trend of agglomeration and cluster, such as Yangtze River Delta. It is therefore implied that the Chinese government ought to provide some guidelines for cities to act as nodes to strengthen intercity linkages.

The outflow effect shows the role of a city in driving another city node to develop, while the inflow effect indicates the dependence of a given city node on others [44]. In this sense, the outflow and 
inflow effects address the level of influencing and being influenced in terms of connectivity direction. As described above, $47 \%$ of city nodes have a larger in-degree than out-degree, while $43 \%$ of city nodes have a smaller one (see Table 3). This signifies that city nodes in China differ slightly from each other in their ways of influencing and being influenced as demonstrated by the capabilities of outflow and inflow of city nodes that are on average identical (0.090). Despite this, Shanghai appears to have the largest capacity of both outflow and inflow, suggesting that it has the greatest impact over other nodes and its development is also strongly supported by others. The development of KIBS sectors requires an abundance of commodities and human capital. Greater inflow than outflow means more capital input than output. Such a situation with larger inflow than outflow equips Shanghai with more resources in order to support its rapid development of KIBS. In contrast, Beijing has a larger outflow than inflow and the inflow-outflow gap is substantial. One of the main reasons might be that Beijing, as China's capital, has the responsibility of facilitating other city nodes to develop. As such, strengthening intercity linkages through enhancing the outflow effect of developed nodes and the inflow effect of less developed nodes can underscore a balance of KIBS development nationwide.

\subsection{Centrality and Power}

Basically, centrality and power are two sides of city degrees-outlines the amount of linkages and the linkages of nodes in a key position respectively. As sketched in Figure 2, neither centrality nor power converts into each other [22]. Guangdong, for example, has a high ranking of centrality, signifying a large amount of linkages in the production chain of KIBS. This matches the reality that Guangdong is one of the most developed regions in China. However, its power is lower than $47 \%$ of all city nodes, suggesting it failed to occupy a central role in the sector nationwide. Therefore, it is found that a city node with large centrality does not mean that it may own a large power in the meantime, and vice versa.

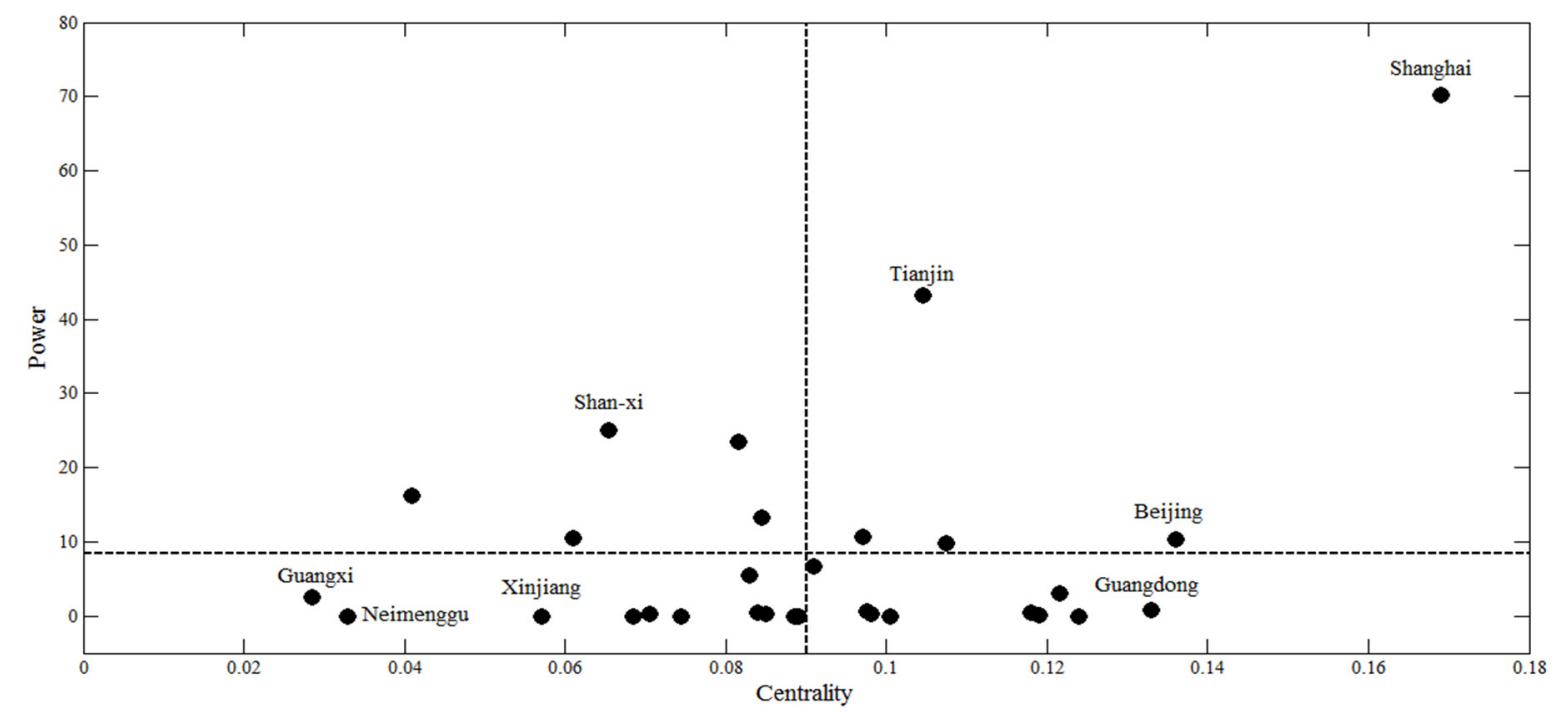

Figure 2. Centrality and power of Chinese city nodes.

In appreciating the asymmetry of city linkages, Neal [22] addressed a catalogue of world city based on the average of centrality and power. Likewise, China's city nodes can be classified into four groups, namely large centrality and huge power (e.g., Shanghai), large centrality and weak power (e.g., Guangdong), small centrality and huge power (e.g., Shan-xi), and small centrality and weak power (e.g., Xinjiang). As such, urban development space for a city might be improved by enhancing its centrality, and the capability of manipulating network resources can be fortified by increasing its power. Therefore, it is implied that the governments have the necessity of identifying disparate profiles of city linkages in line with the catalogue of nodes. For instance, the volume of city linkages in Shan-xi 
is expected to expand, whereas Guangdong has to develop more linkages of city nodes to ameliorate its power.

A city serves as a broker in the network. The power of a city node additionally elaborates the dependence of the node on the paths that cities are connected to in a collective way [12]. It also reveals the advantages of the node on manipulating and utilizing elements flow (e.g., information and materials). Cities with small betweenness have less power and less strength of controlling the flow of elements through the network [12]. As pointed out by Burt [57], such advantages constitute key part of competitive advantages, and delivering less power means weaker competitive advantages. Bearing this in mind, about $27 \%$ of city nodes (Table 3 ) have rare power (the betweenness is 0.000 ), indicating small competitive advantages therein and can inhibit their capability to gain key capital and resources from regional competition. Among these city nodes, most of them are located in the interior of China and Gansu, Qinghai and Xinjiang are the bottom ones that are lag provinces in western China. Such phenomenon accords with regional development of the Matthew effect, "the better and the worse between city nodes", aggravating the gap of KIBS in development between western and eastern regions in China.

\subsection{The Structure of City Network}

Table 4 offers the structural characteristics of city network in China, namely a balanced network as indicated by low hierarchy, a "small world" effect by small average distance and huge compactness, and high cluster by both core area and periphery area. The presence of a balanced network is ascribed to the fact that the rating gaps of KIBS in all of the thirty provinces are minor. Nevertheless, according to Du and Zhao [52], China's city network has a distinctive hierarchy given a whole picture of all sectors. In addition, the compactness of KIBS network (0.908) derived in the study is larger than that in previous studies, such as 0.597 derived by Sun et al. [43] and 0.590 measured by Lv and Fu [44]. A tighter city network will therefore appear in China if the city network is viewed merely in the angle of KIBS.

The "small world" effect mirrors wide and universe city linkages, and these linkages are sparse and represent a high clustered network structure, agreeing with the small world structure of the Chinese industrial network in 1997 and 2005 [44]. The high clustering can further classify nodes into two groups. Shanghai together with Beijing belongs to the core area, while the majority of city nodes are peripheral. This attribute is divergent from the core-sub-periphery-periphery structure of Chinese economic network [58], indicating a more uneven gap of KIBS. KIBS in either Shanghai or Beijing is more matured than that in other places. Nevertheless, the low hierarchy of KIBS-based city network demonstrates that the development gap of KIBS between these two clusters is insignificant, and China is still engaged in a rapid development of KIBS.

KIBS-based city network in China is characterized by a core-periphery structure for a couple of reasons. In fact, it can be ascribed to the development policies of China in the early 21st century. During this period, the Central Government placed much emphasis on many labor-intensive and capital-intensive industries while the knowledge-intensive sector (e.g., KIBS) deserved little attention. Furthermore, the strategy of "the rich first pushing those being rich later" enabled some regions (e.g., Beijing and Shanghai) to take an earlier step to develop KIBS industries.

\subsection{Sustainable Development of KIBS-Based City Network}

The attributes of KIBS-based city network as presented above call for an effective way to implement sustainable urban development.

First, establishing a KIBS-based city network facilitates the achievement of sustainable development at the levels of provinces or cities nationwide. At present, China's economy has been transiting to an era of so-called "new normal". Knowledge intensive services sectors are reconsidered to be a key sector of macro-economy. In appraising experiences from developed countries, researchers have pointed out that the advantages of KIBS are able to fuel urbanization and improve urban 
sustainability to the end $[28,59]$. Therefore, a powerful city network in China should be targeted by allowing KIBS to develop first as a sustainable engine of economy.

Second, more core nodes of KIBS should be incorporated into the interior and to cultivate sub-centers in the nationwide. In the core-periphery structure, most provinces or cities are in periphery while only Beijing and Shanghai stay in the core, emerging with asymmetrical and disproportionate clusters. Due to geographical distance between east and west interior, these two core cities located in the east lend limited driving force for those provinces and cities in the interior of China, especially the southwest region. In order to offset the distance attenuation of core city nodes, sub-centers must allow incurring a core-sub-periphery-periphery network structure. To this end, a balanced regional development can be achieved.

Thirdly, KIBS agglomeration and cluster development via cooperative alliance among cities can be implemented. Industrial agglomeration helps stimulate industrial advancement and maintain environmental integrity [2]. The small world effect of KIBS-based city network in China mirrors wide and impact linkages, indicating a broad interaction and interdependence between city nodes. This property lays a basic foundation for urban collaboration. Especially, those city nodes with closer linkages, short distance or complementary advantages must be powerful in driving economic entities to erect global competitiveness.

\section{Conclusions}

With the increasing intercity communication, problems arising in a city in regard to economy, society and the environment could yield much impact on other cities that are connected to form a larger network. The current era has seen the vital role of knowledge intensive business services in a city network and it spells out endogenous development opportunities in the long run. In this study, three main findings are reached: (1) the degree of city nodes in terms of out-degree, in-degree, and betweenness varies widely from city to city; (2) the hierarchy structure of city network is very tiny; and (3) the whole city network exhibits "a small world effect" and core-periphery structure. It is implied that city network in China displayed a distinctive gap, weakness and compactness of KIBS. Strategies for China to achieve balanced and powerful KIBS development toward urban economic sustainable development can thus be proposed accordingly.

Since urban centrality is determined by both outward and inward linkages, the Chinese government ought to guarantee a balanced urban configuration in line with the outflow effect of those developed nodes as well as the inflow effect of lagged nodes. The centrality suggests that urban sustainability can be improved by widening development opportunities, while the power implies that the improvement can be made by allocating network resources efficiently. In addition, it is very important that the gap between those peripheral nodes and core nodes can be narrowed to ensure harmonious development of urban system. Multi-cores and sub-centers, especially in interior China, are expected to decentralize the distribution of major nodes to improve the holistic function of the city network. Furthermore, KIBS in China has been in such a way that wide and compact city linkages are subject to a small-world effect, which highlights the importance of aggregating inter-city cooperation.

In a nutshell, the research findings lay a useful foundation for future studies to explore network density, clustering coefficient, closeness centrality, eigenvector centrality, or those related to city clustering, and can shed some lights on the role of city network in the attainment of urban sustainability.

Acknowledgments: The authors are grateful to Chongqing University for financing this research project under the Fundamental Research Funds for the Central Universities, No. 106112016 CDJSK 03 XK 08. Gratitude is also due to the anonymous reviewers who put forward many meaningful suggestions.

Author Contributions: The authors contributed to this paper at various stages of the method selection, data analysis, writing and improving process.

Conflicts of Interest: The authors declare no conflict of interest. 


\section{References}

1. Hassan, A.M.; Lee, H. Toward the sustainable development of urban areas: An overview of global trends in trials and policies. Land Use Policy 2015, 48, 199-212. [CrossRef]

2. Zhu, J. Making urbanisation compact and equal: Integrating rural villages into urban communities in Kunshan, China. Urban Stud. 2016. [CrossRef]

3. Metcalfe, J.S.; Ramlogan, R. Limits to the economy of knowledge and knowledge of the economy. Futures 2005, 37, 655-674. [CrossRef]

4. Yigitcanlar, T. Planning for knowledge-based urban development: Global perspectives. J. Knowl. Manag. 2009, 13, 228-242.

5. Knight, R. Knowledge-based development: Policy and planning implications for cities. Urban Stud. 1995, 32, 225-260. [CrossRef]

6. Yigitcanlar, T. Position paper: Redefining knowledge-based urban development. Int. J. Knowl. Based Dev. 2011. [CrossRef]

7. Batten, D.F. Network cities: Creative urban agglomerations for the 21st century. Urban Stud. 1995, 32, 313-327. [CrossRef]

8. Leng, B.; Yang, Y.; Li, Y.; Zhao, S. Spatial characteristics and complex analysis: A perspective from basic activities of urban networks in China. Acta Geogr. Sin. 2011, 66, 199-211.

9. Yang, Y.; Leng, B.; Tan, Y.; Li, T. Review on world city studies and their implications in urban systems. Geogr. Res. 2011, 30, 1009-1020.

10. Timberlake, M.; Wei, Y.D.; Ma, X.; Hao, J. Global cities with Chinese characteristics. Cities 2014, 41, 162-170. [CrossRef]

11. Meijers, E. From central place to network model: Theory and evidence of a paradigm change. Tijdschr. Econ. Soc. Geogr. 2007, 98, 245-259. [CrossRef]

12. Alderson, A.S.; Beckfield, J. Power and position in the world city system. Am. J. Sociol. 2004, 109, 811-851. [CrossRef]

13. Short, J.R. Black holes and loose connections in a global urban network. Prof. Geogr. 2004, 56, $295-302$.

14. Sang, M.; Tan, C. A new trend in regional economics: Research on regional economic network. Hum. Geogr. 2014, 29, 28-34.

15. Nordlund, C. A critical comment on the Taylor approach for measuring world city interlock linkages. Geogr. Anal. 2004, 36, 290-296. [CrossRef]

16. Zhao, M.; Wu, K.; Liu, X.; Ben, D. A novel method for approximating intercity networks: An empirical comparison for validating the city networks in two Chinese city-regions. J. Geogr. Sci. 2015, 25, 337-354. [CrossRef]

17. Neal, Z. Validity in world city network measurements. Tijdschr. Econ. Soc. Geogr. 2014, 105, 427-443. [CrossRef]

18. Stanley, B. Middle East city networks and the "new urbanism". Cities 2005, 22, 189-199. [CrossRef]

19. Smith, D.A.; Timberlake, M.F. World city networks and hierarchies, 1977-1997: An empirical analysis of global air travel links. Am. Behav. Sci. 2001, 44, 1656-1678. [CrossRef]

20. Liu, J. Lectures on Whole Network Approach-A Practical Guide to UCINET, 2nd ed.; Gezhi Press Shanghai People's Publishing House: Shanghai, China, 2014.

21. Friedmann, J.; Wolff, G. World city formation: An agenda for research and action. Int. J. Urban Reg. Res. 1982, 6, 309-344. [CrossRef]

22. Neal, Z. Differentiating centrality and power in the world city network. Urban Stud. 2011, 48, $2733-2748$. [CrossRef]

23. Zhao, Y.; Wang, C. Literature review of cluster innovation and innovation system in knowledge intensive business services. Sci. Technol. Prog. Policy 2009, 26, 195-200.

24. Yang, F. Research on the path of KIBS network capabilities and corporate performance. Hum. Soc. Sci. 2013, 5, 177-180.

25. Bai, O.; Wei, J. Research on innovation trajectory evolution in knowledge-intensive business service industry: A comparative study on P-KIBS and T-KIBS. J. Beijing Technol. Bus. Univ. (Soc. Sci.) 2014, 29, 8-21.

26. Wei, J. Functions of knowledge-intensive business service in macro innovation system. Stud. Sci. Sci. 2004, $22,141-145$. 
27. Yigitcanlar, T.; Sarimin, M.; McCartney, R. Developing a knowledgebased urban development analysis framework: The case of multimedia super corridor, Malaysia. In Proceedings of the 5th International Forum on Knowledge Asset Dynamics, Matera, Italy, 24-25 June 2010.

28. Zhang, X.; Wang, G.; Bi, X. The impact of network centrality and knowledge innovation ability on the Innovation performance of KIBS enterprises. Econ. Probl. 2013, 8, 92-96.

29. Taylor, P.J. Leading world cities: Empirical evaluations of urban nodes in multiple networks. Urban Stud. 2005, 42, 1593-1608. [CrossRef]

30. Camagni, R.P.; Salone, C. Network urban structures in northern Italy: Elements for a theoretical framework. Urban Stud. 1993, 30, 1053-1064. [CrossRef]

31. Taylor, P.J. Specification of the world city network. Geogr. Anal. 2001, 33, 181-194. [CrossRef]

32. Derudder, B.; Timberlake, M.; Witlox, F. Introduction: Mapping changes in urban systems. Urban Stud. 2010, 47, 1835-1841. [CrossRef]

33. Coelho, F.C.; Cruz, O.G.; Codeço, C.T. Epigrass: A tool to study disease spread in complex networks. Sour. Code Biol. Med. 2008. [CrossRef] [PubMed]

34. Nljkamp, P. Handbook of Regional and Urban Economics: Regional Economics (Vol. 1); Economic Science Press: Beijing, China, 2001.

35. Zhang, Y.; Zheng, H.; Fath, B.D.; Liu, H.; Yang, Z.; Liu, G.; Su, M. Ecological network analysis of an urban metabolic system based on in put-output tables: Model development and case study for Beijing. Sci. Total Environ. 2014, 468, 642-653. [CrossRef] [PubMed]

36. Pan, W.; Zhang, R. Spatial structure of China's economy: Feedback loops and hierarchy. Manag. Rev. 2009, $21,42-47$.

37. Liu, H.; Liu, W.; Liu, Z. The quantitative study on inter-regional industry transfer. China Ind. Econ. 2011, 6, 79-88.

38. Wu, F.; Zhu, L. Industry linkages and its spillover and feedback effect among three regions in China: An empirical study based on multi-regional input-output analysis technology. Nankai Econ. Stud. 2010, 5, 140-152.

39. Liu, H.; Zhang, Y. Ecological network analysis of urban metabolism based on input-output table. Procedia Environ. Sci. 2012, 13, 1616-1623. [CrossRef]

40. Wang, Y.; Ge, Y. Analysis on the connectivity features of input-output of the industrial structure in China. Manag. World 2007, 2, 61-68.

41. Liu, G. Research on the consumption coefficient of the input-output analysis. Stat. Decis. 2006, 2, 12-14.

42. Xiang, R. A new probe on the functions of input-output coefficients and their empirical analysis. Stat. Inf. Forum 2008, 23, 5-9.

43. Sun, L.; Xue, B.; Zhang, Z.; Zhang, L.; Geng, R. A SNA-based measurement on industrial structure change and industrial networking of China. Ecol. Econ. 2014, 30, 83-87.

44. Lv, K.; Fu, Y. Construction and structural measurement of the inter-regional industrial spatial networks in China. Econ. Geogr. 2010, 30, 1785-1791.

45. Wood, P. Knowledge-intensive services and urban innovativeness. Urban Stud. 2002, 39, 993-1002. [CrossRef]

46. Daniels, P.W.; Bryson, J.R. Manufacturing services and servicing manufacturing: Knowledge based cities and changing forms of production. Urban Stud. 2002, 39, 977-991. [CrossRef]

47. Johnston, A.; Huggins, R. The Spatio-relational nature of urban innovation systems: Universities, knowledge intensive business service firms, and collaborative networks. J. Urban Technol. 2016, 1-24. [CrossRef]

48. Cuadrado-Roura, J.R. The location of service industries. In Service Industries and Regions; Springer Berlin: Heidelberg, Germany, 2013; pp. 253-284.

49. Huggins, R. The growth of knowledge-intensive business services: Innovation, markets and networks. Eur. Plan. Stud. 2011, 19, 1459-1480. [CrossRef]

50. Ženka, J.; Novotný, J.; Slach, O.; Ivan, I. Spatial distribution of knowledge-intensive business services in a small post-communist economy. J. Knowl. Econ. 2015, 1-22. [CrossRef]

51. Wood, P. The regional significance of knowledge-intensive services in Europe. Innov. Eur. J. Soc. Sci. Res. 2006, 19, 51-66. [CrossRef]

52. Du, H.; Zhao, S. An empirical study on the adjustment of industry structure in China: An application of social network analysis. Manag. Rev. 2013, 25, 38-47. 
53. Liu, Y.; Dai, L. Economic contact analysis with network structure of urban agglomeration around the Poyang Lake based on SNA. Resour. Environ. Yangtze Basin 2013, 22, 263-271.

54. Wang, S.; Li, X. Research on decision-making of sustainable travel of country from the perspective of social network: A case study of Yangjiabu country in Weifang,Shandong. Chin. Rural Econ. 2011, 3, 59-69.

55. Taylor, P.; Derudder, B.; Hoyler, M.; Ni, P.; Witlox, F. City-dyad analyses of China's integration into the world city network. Urban Stud. 2013, 51, 868-882. [CrossRef]

56. The Laboratory of Regional Sustainable Development Modeling, Institute of Geographical Sciences and Natural Resource Research, Chinese Academy of Sciences (CAS). Available online: http:/ / english.igsnrr.cas. cn/kl/201007/t20100715_56478.html (accessed on 25 May 2016).

57. Burt, P.S. Structural Holes: The Social Structure; Lin, M.; Li, L.; Lin, H., Translators; Gezhi Press Shanghai People's Publishing House: Shanghai, China, 2008.

58. Dou, J.M.; Zhang, K. Evolution trend of China' s economy pattern and urban network system. Urban Probl. 2015, 7, 54-61.

59. Li, W. Effects of KIBS on improving Chinese industry efficiency: From the perspective of cost. Econ. Probl. $2012,7,70-73$.

(C) 2016 by the authors; licensee MDPI, Basel, Switzerland. This article is an open access article distributed under the terms and conditions of the Creative Commons Attribution (CC-BY) license (http://creativecommons.org/licenses/by/4.0/). 